\title{
Dysphagia from esophageal tuberculosis in a patient with undiagnosed HIV infection
}

A 57-year-old woman from Ethiopia presented with a 1-month history of dysphagia and odynophagia, with associated decreased appetite and unintentional weight loss. The patient had a remote history of treated pulmonary tuberculosis.

The physical examination was unremarkable. An esophagogram revealed diffuse irregularities in the mucosa with ulceration ( $\mathbf{F i g . 1}$ ). Laboratory tests revealed pancytopenia, chronic hepatitis $B$, and HIV infection, with a CD4 cell count of 120 cells/mm3. Computed tomography of the chest and abdomen showed splenomegaly, pulmonary nodules with ground-glass opacities, and esophageal thickening. Esophagogastroduodenoscopy revealed a nodular, inflamed, and aperistaltic esophagus extending from $25 \mathrm{~cm}$ to $31 \mathrm{~cm}$ from the incisors without any ulcers ( $\mathbf{F i g . 2 , ~} \mathbf{2}$ Video $\mathbf{1}$ ).

Multiple tissue samples were sent for histopathological examination and tissue culture. Pathological examination of the esophageal biopsy revealed necrotizing granulomas with negative acid-fast stain (ฉ Fig.3). Bronchoalveolar lavage (BAL) was performed for evaluation of ground- glass opacities. Polymerase chain reaction for Mycobacterium tuberculosis (MTB) on esophageal biopsy was positive, and tissue culture from both esophageal biopsy and BAL later grew MTB. The patient was initiated on four-drug antitubercular therapy.

Gastrointestinal tuberculosis most commonly involves the terminal ileum and cecum, with only $0.3 \%$ of cases involving the esophagus [1]. Moreover, it is seen in developing countries with a high prevalence of tuberculosis. There are no specific diagnostic endoscopic features, but commonly reported endoscopic features are linear noncircumferential midesophageal ulcers with elevated edges $[2,3]$. Direct translocation of bacteria from mediastinal involvement is hypothesized and cases of tracheoesophageal fistula have also been reported [4]. Endoscopic ultrasound can also assist to demonstrate infiltration of the esophageal wall by lymph nodes [5]. Our case highlights the rare involvement of the esophagus in tuberculosis, presenting as dysphagia and odynophagia in an immunocompromised host. A high clinical suspicion is required, even if pathology is negative for MTB, especially in patients from countries with a high prevalence of MTB.

Endoscopy_UCTN_Code_CCL_1AB_ 2AC_3AZ

\section{Competing interests}

None

\section{The Authors}

Rajat Garg', Sean Carter², Mohammed Barawi ${ }^{3}$

1 Department of Internal Medicine, St. John Hospital and Medical Center, Detroit, Michigan, United States

2 Central Michigan University College of Medicine, Mt Pleasant, Michigan, United States

3 Division of Gastroenterology and Hepatology, St. John Hospital and Medical Center, Detroit, Michigan, United States

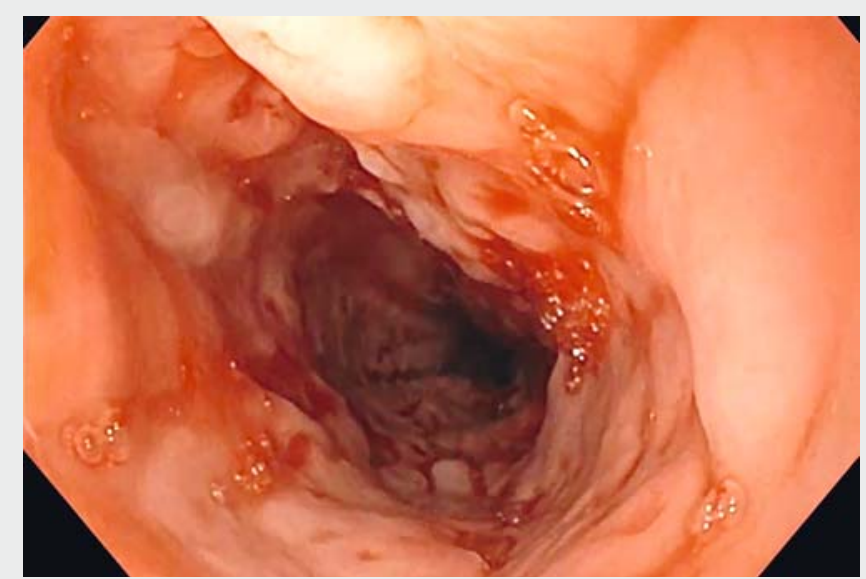

Video 1 Esophagogastroduodenoscopy showing nodular esophageal mucosa in the mid-esophagus from $25 \mathrm{~cm}$ to $31 \mathrm{~cm}$ from the incisors. It also shows friable mucosa with spontaneous oozing. Also note esophageal thickening and absence of peristalsis. 

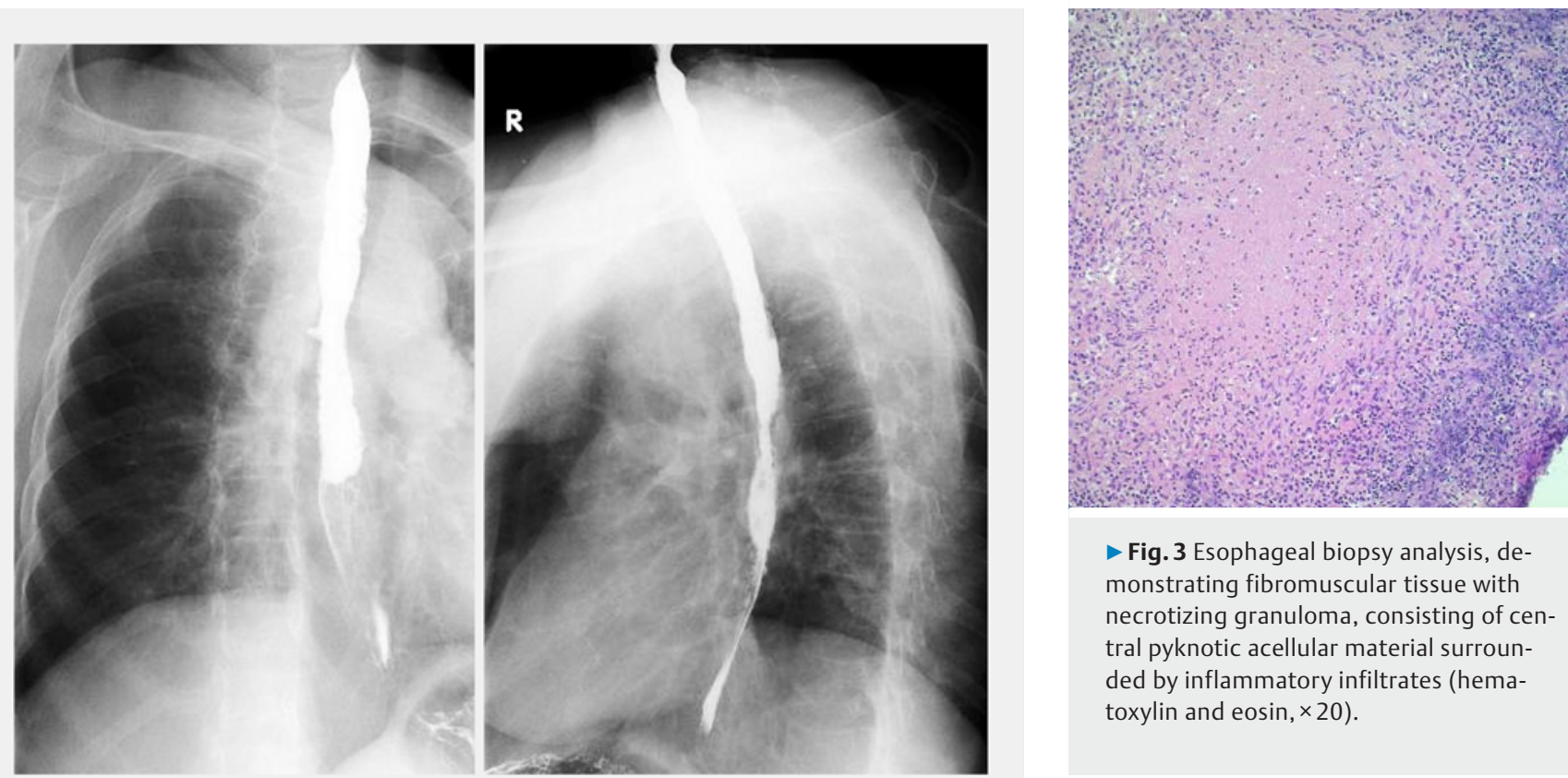

-Fig. 3 Esophageal biopsy analysis, demonstrating fibromuscular tissue with necrotizing granuloma, consisting of central pyknotic acellular material surrounded by inflammatory infiltrates (hematoxylin and eosin, $\times 20$ ).

- Fig. 1 Esophagram showing diffuse irregularity of esophageal mucosa with ulceration sparing the distal portion.

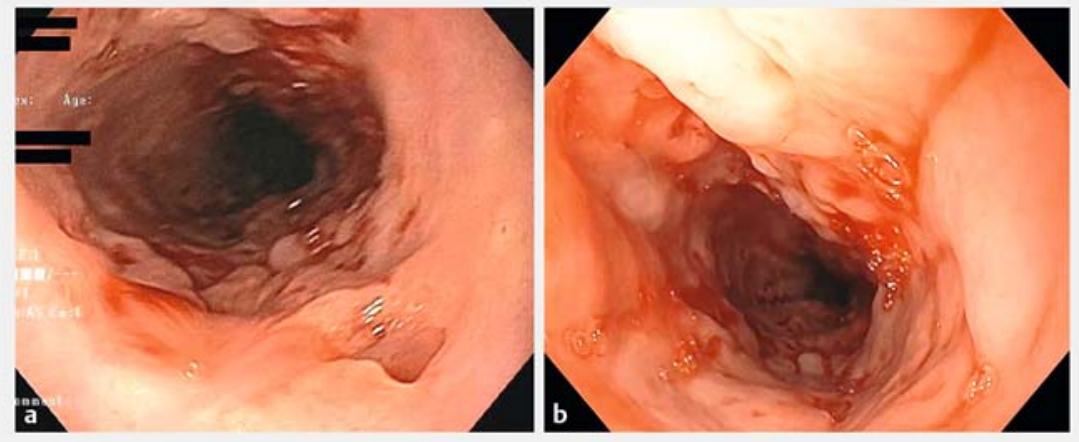

- Fig. 2 Esophagogastroduodenoscopy. a Fibrotic and nodular esophagus with a pseudodiverticulum. b Multiple nodules in the upper esophagus.

\section{Corresponding author}

\section{Rajat Garg, MD}

Department of Internal Medicine, 19251,

Mack Ave, Suite 335, Grosse Pointe Woods,

MI, 48236, USA

Fax: +1-313-343-8747

drgargrajat@gmail.com

\section{References}

[1] Marshall JB. Tuberculosis of the gastrointestinal tract and peritoneum. Am J Gastroenterol 1993; 88: 989-999

[2] Jain SK, Jain S, Jain M et al. Esophageal tuberculosis: is it so rare? Report of 12 cases and review of the literature Am J Gastroenterol 2002; 97: 287-291
[3] Park JH, Kim SU, Sohn JW et al. Endoscopic findings and clinical features of esophageal tuberculosis. Scand J Gastroenterol 2010; 45: $1269-1272$

[4] Abid S, Jafri W, Hamid S et al. Endoscopic features of esophageal tuberculosis. Gastrointest Endosc 2003; 57: 759-762

[5] Sharma V, Rana SS, Chhabra P et al. Primary esophageal tuberculosis mimicking esophageal cancer with vascular involvement. Endosc Ultrasound 2016; 5: 61-62

\section{Bibliography}

DOI https://doi.org/10.1055/s-0043-110667

Published online: 14.6.2017

Endoscopy 2017; 49: E195-E196

(c) Georg Thieme Verlag KG

Stuttgart · New York

ISSN 0013-726X

\section{ENDOSCOPY E-VIDEOS}

https://eref.thieme.de/e-videos

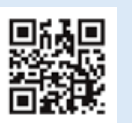

Endoscopy E-Videos is a free access online section, reporting on interesting cases and new

techniques in gastroenterological endoscopy. All papers include a high quality video and all contributions are freely accessible online.

This section has its own submission website at

https://mc.manuscriptcentral.com/e-videos 